\title{
Partial persistence of the primitive lateral basilovertebral anastomosis of Padget
}

\author{
Persistência parcial da anastomose basilovertebral primitiva lateral de Padget \\ Matheus Kahakura Franco PEDRO',2, Felipe CONSTANZO³, Guilherme José AGNOLETTO4, \\ André Giacomelli LEAL ${ }^{2,5}$, Murilo Sousa MENESES ${ }^{2,5}$
}

\begin{abstract}
A hypertense, smoker, and alcoholic 30-year-old male presented with vertigo and multidirectional nystagmus lasting 30 days. Magnetic Resonance Imaging (MRI) showed subacute vermian infarction (Figures $1 \mathrm{~A}$ and $1 \mathrm{~B}$ ). He underwent digital subtraction angiography (Figures 1C and 1D), which revealed duplication of the vertebrobasilar circulation through a branch of the right vertebral artery, connected to the main circulation by a hypoplastic branch, compatible with partial persistence of the primitive lateral basilovertebral anastomosis of Padget (PLBA) originating the
\end{abstract}

left posterior inferior cerebellar artery (Figures 2A and 2B), an embryonic remnant. PLBA persistence increases stroke chances because of the abnormal pattern of arterial supply territories and subsequent deficient collaterality ${ }^{1,2}$.

\section{ACKNOWLEDGEMENTS}

The authors thank Erasmo B. Silva Jr., from Instituto de Neurologia de Curitiba, for the illustrations.

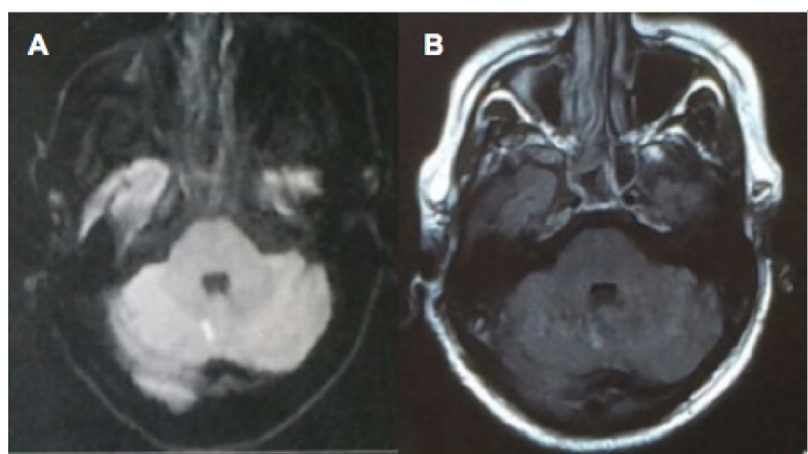

C

D

Figure 1. Axial diffusion weighted [DWI] (A) and Fluid attenuated inversion recovery [FLAIR] (B) images depict a subacute infarction area in the cerebellar vermis. Transfacial (C) and lateral (D) digital subtraction angiography with right vertebral injection images depict stenosis of the distal segment of the vertebral artery (V4) with primitive lateral basilovertebral anastomosis (black arrow) supplying the posterior inferior cerebellar artery (PICA) (hollow arrow); the anastomosis also includes a branch to the basilar artery (curved arrow), which is also connected to the anterior spinal artery (arrowhead).

\footnotetext{
${ }^{1}$ Instituto de Neurologia de Curitiba, Departamento de Neurologia, Curitiba PR, Brazil.

${ }^{2}$ Instituto de Neurologia de Curitiba, Departamento de Neurocirurgia Endovascular e Neurorradiologia Intervencionista, Curitiba PR, Brazil.

${ }^{3}$ Clínica Biobío, Departamento de Cirurgia Neurológica, Concepción, Chile.

«Utah Health, Department of Neurosurgery, Salt Lake City, United States of America.

5 Instituto de Neurologia de Curitiba, Departamento de Neurocirurgia, Curitiba PR, Brazil.

Matheus Kahakura Franco PEDRO iD https://orcid.org/0000-0003-1166-9722; Felipe CONSTANZO ID https://orcid.org/0000-0002-6736-7195;

Guilherme José AGNOLETTO (iD https://orcid.org/0000-0001-8471-9255;André Giacomelli LEAL (D) https://orcid.org/0000-0002-1001-6431;

Murilo Sousa MENESES (D) https://orcid.org/0000-0002-4514-7079

Correspondence: Matheus Kahakura Franco Pedro; E-mail: matheuskfpedro@hotmail.com

Conflict of interest: There is no conflict of interest to declare.
}

Authors' contributions: MKFP: manuscript composition. FC: manuscript composition. GJA: manuscript composition. AGL: manuscript review.

MSM: manuscript review.

Received on March 27, 2020; Received in its final form on May 18, 2020; Accepted on July 28, 2020. 

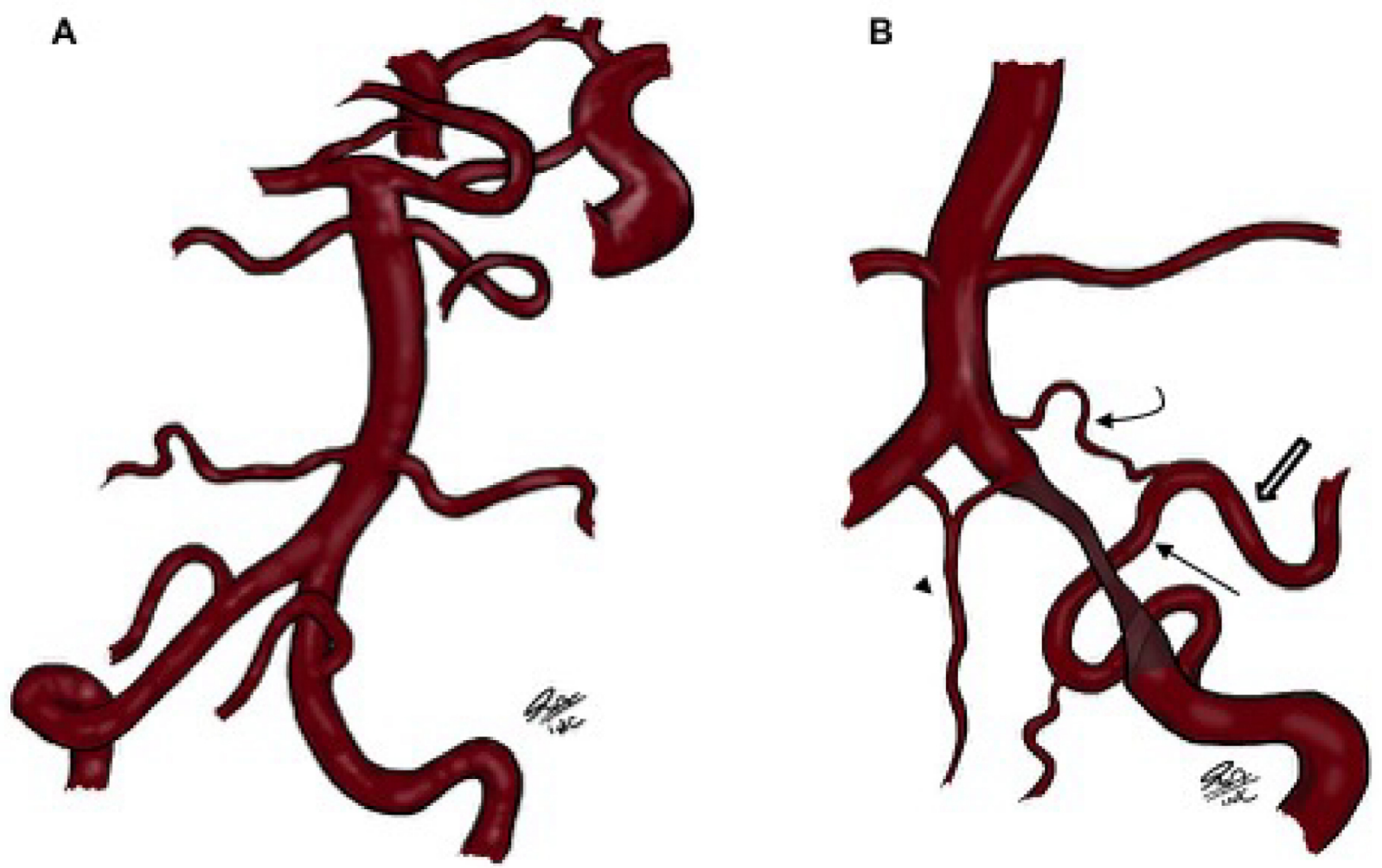

Figure 2. Illustrative drawings depict the standard posterior circulation anatomical disposition (A), in right posterior oblique view, and the patient's variant (B), in posterior view. While in most individuals both vertebral arteries connect to form the basilar artery, originating the PICA on their V4 segments, in this case such segment is hypoplastic; the anastomosis (black arrow) originates from the vertebral artery and develops the PICA (hollow arrow), with another smaller branch connecting this system to the basilar artery (curved arrow), after the emergence of the anterior spinal artery (arrowhead).

\section{References}

1. $\quad$ Gregg L, Gailloud P. The role of the primitive lateral basilovertebral anastomosis of Padget in variations of the vertebrobasilar arterial system. Anat Rec (Hoboken). 2017 Nov;300(11):2025-38. https://doi. org/10.1002/ar.23633
2. $\quad$ Morris P. Practical Neuroangiography. 3. ed. Philadelphia: Wolters Kluwer; 2013. 